\title{
REGISTROS DE LA AMBIGÜEDAD EN LA NARRATIVA CERVANTINA
}

En las narraciones cervantinas hay numerosas ocasiones en que se nos ofrece sólo una versión aproximada de lo que sucede o se dice en la ficticia realidad que se cuenta. Las palabras del narrador de La fuerza de la sangre cuando Leocadia relata su historia a doña Estefanía, la madre de su violador, son «ejemplares» en este aspecto: «Destas razones tomó ocasión de decirle, una vez que se halló sola con ella, las que con acuerdo de sus padres había determinado de decille, que fueron éstas $o$ otras semejantes ${ }^{1}$. La distancia que media entre la reproducción de la realidad y ésta es poca - según el narrador-, pero existe. Si el lector quiere que se le cuente «la verdad», absténgase de leer los relatos cervantinos; en ellos, una sola verdad no existe.

¿Es interesante el relato de las aventuras de Periandro en el Persiles? Depende de quien lo escuche. Lo cuenta con «donaire» y «buen estilo», según admite aun el público más reacio que está dentro del propio texto, y no digamos el atento: «La que con más gusto escuchaba a Periandro era la bella Sinforosa, estando pendiente de sus palabras como con las cadenas que salían de la boca de Hércules» "; pero su plática es para Mauricio y Ladislao "algo larga y traída no muy a propósito" ${ }^{3}$. ¿Qué nos parece a nosotros los lectores que estamos fuera del libro? ¿Tiene razón Sinforosa o Transila, que dice que «ora se dilate o se sucinte en lo que dice,

1 Miguel de Cervantes, Novelas ejemplares, edic. de Rosa Navarro. Madrid, Alianza Editorial, 1995, I, p. 379.

2 Miguel De Cervantes, Los trabajos de Persiles y Sigismunda, edic. de Carlos Romero. Madrid, Cátedra, 1997, p. 353.

3 Ibid., p. 348. 
todo es bueno y todo da gusto»? ¿La tiene Mauricio al decirle a su hija Transila: "Paréceme, Transila, que con menos palabras y más sucintos discursos pudiera Periandro contar los de su vida»? ${ }^{4}$. ¿Es farragoso y lento su relato? ¿Nos lo hace parecer la opinión de parte de su público que, al incluirla el narrador, retarda más el desenlace de la historia?.

Uno de los episodios de este relato es puesto en duda por los que escuchan a Periandro, aunque sin atreverse a manifestarlo. Es el fantástico salto del fogoso caballo desde la punta de una peña sobre el mar helado. Dice el narrador: «Duro se le hizo a Mauricio el terrible salto del caballo tan sin lisión: que quisiera él, por lo menos, que se hubiera quebrado tres o cuatro piernas, porque no dejara Periandro tan a la cortesía de los que le escuchaban la creencia de tan desaforado salto». Y añade: "pero el crédito que todos tenían de Periandro les hizo no pasar adelante con la duda del no creerle: que, así como es pena del mentiroso que, cuando diga verdad no se le crea, así es gloria del bien acreditado el ser creído cuando diga mentira» ${ }^{5}$. ¿El narrador se inclina por la incredulidad de Mauricio? ¿Es él quien califica el salto de «desaforado»? ¿No asume, por tanto, él un acto tan inverosímil? ¿Nos está diciendo que Periandro miente? ¿La comparación («así como es pena del mentiroso...») desborda su espacio y contamina los hechos o es sólo recurso retórico para explicar el silencio del público?. El narrador abandona ese espacio de duda y dice: «Y como no pudieron estorbar los pensamientos de Mauricio la plática de Periandro, prosiguió la suya diciendo». ¿Fueron sólo los pensamientos de Mauricio? La sucesión de interrogaciones retóricas que estoy formulando es sólo el subrayado de ese espacio que media entre la realidad y lo contado y que figura en el propio texto: es una de las múltiples formas de la ambigüedad cervantina. Riley dijo del pasaje: "Cervantes impone maliciosamente a los oyentes y al lector el terrible dilema de aceptar lo increíble o dudar de una persona que goza del mayor crédito" ${ }^{6}$. En realidad, Cervantes no impone nada; crea un mundo de ficción cuya lectura puede ser múltiple.

No puedo menos que reproducir las palabras de ese narrador, que se introduce con su yo en el relato, tras el fin de la historia de Periandro, para que observen las «capas de realidades posibles» -si me admiten el término-:

No sé si tenga por cierto, de manera que ose afirmar, que Mauricio y algunos de los más oyentes se holgaron de que Periandro pusiese fin en

Ibid., p. 369

5 Ibid., p. 412.

6 EdWARD C. RILEY, Teoría de la novela en Cervantes. Madrid, Taurus, 1971, p. 298. 
su plática, porque las más veces, las que son largas, aunque sean de importancia, suelen ser desabridas. Este pensamiento pudo tener Auristela, pues no quiso acreditarle con comenzar por entonces la historia de sus acontecimientos; que puesto que habían sido pocos desde que fue robada de poder de Arnaldo hasta que Periandro la halló en la isla Bárbara, no quiso añadirlos hasta mejor coyuntura; ni aunque quisiera, tuviera lugar para hacerlo, porque se lo estorbara una nave que vieron venir por alta mar, encaminada a la isla, con todas las velas tendidas...?

Su afirmación inicial se presenta como dudosa: «no sé si tenga por cierto...», a pesar de que los antecedentes nos lleven a creer que no se equivoca - la coherencia interna del relato-. Pero formula luego una segunda suposición que se asienta en un hecho inexistente: Auristela tal vez encontró también premioso el relato de Periandro porque no quiso empezar el suyo ( Este pensamiento pudo tener Auristela...»). Pero si no lo empezó no fue por este posible juicio, sino porque la llegada de una nave lo aplazó («ni aunque quisiera, tuviera lugar para hacerlo...»). El narrador no se sitúa en el conocimiento seguro, en "la verdad», sino sólo en el terreno de las hipótesis, que podrían ser desmentidas lo mismo que confirmadas.

Al comienzo del libro segundo, el narrador, que - como él dicees sólo traductor del relato, prescinde de una digresión del «historiador» sobre los celos: «Parece que el autor desta historia sabía más de enamorado que de historiador, porque casi este primer capítulo de la entrada del segundo libro le gasta todo en una difinición de celos, ocasionados de los que mostró tener Auristela por lo que le contó el capitán del navío; pero en esta tradución, que lo es, se quita por prolija, y por cosa en muchas partes referida y ventilada, y se viene a la verdad del caso, que fue que, cambiándose el viento y enmarañándose las nubes, cerró la noche escura y tenebrosa...» ${ }^{8}$.

Pero ésta es una sólo de las varias formas posibles de la ambigüedad cervantina, de la que se podría sumar ejemplos. Algún episodio del Quijote, como el de la cueva de Montesinos, ofrecería bien conocidos matices al relato que el personaje presenta como cierto y que es recibido de distintas formas por los dos que lo escuchan. A ello se le añade - como es bien sabido- que el narrador dice que el traductor copia las dudas del historiador (el moro y, por tanto, mentiroso, Cide Hamete Benengeli) sobre el posible carácter apócrifo del episodio, que estaban escritas al margen del texto. Concluyen con un apóstrofe al lector: «Tú, letor, pues eres prudente, juzga lo que te pareciere, que yo no debo ni puedo más; puesto que se tiene por cierto que, al tiempo de su fin y muerte, dicen que

7 Los trabajos de Persiles y Sigismunda, pp. 416-17.

8 Ibid., p. 275. 
se retrató della, y dijo que él la había inventado, por parecerle que convenía y cuadraba bien con las aventuras que había leído en sus historias." ${ }^{9}$. Como dice Aurora Egido: «El perspectivismo, así como el ejercicio de la imitación compuesta, obligan además a considerar el episodio no sólo como logro máximo de creación que supera las más variadas fuentes, sino como muestra de un texto que se ilumina y entiende de formas muy diversas, según sea contemplado desde el punto de vista de su relator único, don Quijote, desde el de los oyentes privilegiados, Sancho y el Primo, o desde la sutil coartada de Cervantes que se escuda y confunde al lector, so pretexto de dejarlo en libertad, con el añadido del apócrifo» ${ }^{10}$.

En el mismo Persiles hay un mínimo suceso que habla de otro registro de la ambigüedad del genial novelista esta vez en el campo de la organización de la materia contada: cómo en sus obras desaparecen los límites entre los géneros.

Yendo hacia Barcelona, al salir de Villarreal —en Castellón-, «les salió al encuentro una zagala o pastora valenciana, vestida a lo del campo, limpia como el sol, y hermosa como él y como la luna, la cual en su graciosa lengua, sin hablarles alguna palabra primero, y sin hacerles ceremonia de comedimiento alguno, dijo: - ¿Señores, pedirlos he o darlos he?».

Periandro, sin duda ninguna sobre el asunto de la pregunta, responde: «-Hermosa zagala, si son celos, ni los pidas ni los des, porque si los pides, menoscabas tu estimación, y si los das, tu crédito; y si es que el que te ama tiene entendimiento, conociendo tu valor, te estimará y querrá bien, y si no le tiene, ¿para qué quieres que te quiera?». La muchacha asiente y sentencia: «-Bien has dicho [...] Y diciendo adiós, volvió las espaldas y se entró en la espesura de los árboles, dejándolos admirados con su pregunta, con su presteza y con su hermosura» ${ }^{11}$.

El diálogo no tiene continuidad, y la pastora no reaparece; el episodio es una pincelada gratuita, pero maestra. Nos ofrece a un personaje de novela bizantina que reconoce a otro de otro tipo de relato, de un libro de pastores, y sabe acomodarse a su discurso, sabe resolver el «caso» que plantea (los personajes de relatos pastoriles son - viven- o proponen como tema de discusión «casos» amorosos).

En el quinto libro de la Galatea, Timbrio narra su vida rodeado de pastores que «con maravillosa atención» le escuchan. Cuenta

\footnotetext{
9 Miguel de Cervantes, Don Quijote de la Mancha, edic. de Martín de Riquer. Barcelona, Planeta, 1962, p. 762; II, 24.

10 "La cueva de Montesinos y la tradición erasmista de ultratumba", en Cervantes y las puertas del sueño. Barcelona, PPU,1994, p. 139.

11 Los trabajos de Persiles y Sigismunda, pp. 562-63.
} 
cómo «aquejado de la memoria de» sus «desventuras», perdió el sentido. Y al abrir los ojos, «halléme puesta la cabeza en las faldas de una mujer vestida en hábito de peregrina, y a mi lado estaba otra con el mesmo traje adornada» ${ }^{12}$. Son Nísida y Blanca, el relato de cuyas aventuras Timbrio reproduce y une éstas a las suyas: es un episodio de novela bizantina con ataque de barcos turcos, naufragio, cautividad (que concluye en donde empezó la de Cervantes: en la costa catalana) y abundantes peripecias.

No olvidemos que en la segunda parte del Quijote, aparece un grupo de jóvenes nobles disfrazados de pastores (II, 58), que están ensayando un égloga de Garcilaso y otra de Camoens, pero que además han leído la primera parte del Quijote y reconocen al personaje. La primera réplica de don Quijote al parlamento de una de las hermosas zagalas se ajusta totalmente al disfraz y al entretenimiento: alaba su hermosura mencionando la fábula de Diana y Acteón: «Por cierto, hermosísima señora, que no debió de quedar más suspenso ni admirado Acteón cuando vio al improviso bañarse en las aguas a Diana, como yo he quedado atónito en ver vuestra belleza» ${ }^{13}$. Don Quijote sabe muy bien cómo pasar de personaje de libro de caballerías a uno de libro de pastores: basta cambiarse el nombre y el traje. Precisamente al volver, vencido, camino de su aldea, al prado donde encontraron a los cortesanos disfrazados, dirá a Sancho: «Éste es el prado donde topamos a las bizarras pastoras y gallardos pastores que en él querían renovar e imitar a la pastoral Arcadia, pensamiento tan nuevo como discreto, a cuya imitación, si es que a ti te parece bien, querría, joh Sancho!, que nos convirtiésemos en pastores, siquiera el tiempo que tengo de estar recogido. Yo compraré algunas ovejas, y todas las demás cosas que al pastoral ejercicio son necesarias, y llamándome yo el pastor Quijotiz, y tú el pastor Pancino, nos andaremos por los montes, por las selvas y por los prados, cantando aquí, endechando allí, bebiendo de los líquidos arroyuelos, o de los caudalosos ríos» (II, 67). No tendrá ni que cambiar el nombre a Dulcinea, pues, como le dice a Sancho, «el de mi señora cuadra así al de pastora como al de princesa, no hay para qué cansarme en buscar otro que mejor le venga» ${ }^{14}$.

Cervantes sabe pasar en un instante de un género a otro de novela o pensar en transformar a un personaje de un tipo de ellas en otro, pero su audacia va más allá e incorpora escenas teatrales o incluso pequeñas piezas dramáticas en sus obras narrativas. Con-

\footnotetext{
12 Miguel de Cervantes, Galatea, edic. de F. Sevilla y A. Rey Hazas. Alcalá de Henares, Centro de Estudios Cervantinos, 1994, p. 289.

13 Don Quijote de la Mancha, edic. cit., p. 1022

14 Ibid., p. 1094.
} 
vierte a personajes de sus novelas en espectadores de escenas y crea así planos superpuestos en sus obras. En la Galatea, «una hermosa pastorcilla de hasta edad de quince años, con su zurrón al hombro y cayado en la mano" llama la atención a los personajes que estaban con su charla trazando la urdimbre de la novela y les exhorta a seguirla hasta mostrarles una escena que aparece como foto fija: «Volvieron todos los ojos a la parte que la pastora señalaba y vieron que al pie de un verde sauce estaba arrimada una pastora, vestida como cazadora ninfa, con una rica aljaba que del lado le pendía y un encorvado arco en las manos, con sus hermosos y rubios cabellos cogidos con una verde guirnalda. El pastor estaba ante ella de rodillas, con un cordel echado a la garganta y un cuchillo desenvainado en la derecha mano, y con la izquierda tenía asida a la pastora de un blanco cendal que encima de los vestidos traía. Mostraba la pastora ceño en su rostro y estar disgustada de que el pastor allí por fuerza la detuviese» ${ }^{15}$. Cuando la pastora se siente observada, actúa.

El final de Las dos doncellas ofrece una sucesión de escenas contempladas por distintos personajes. Cuando los primeros observadores se incorporan a lo que al comienzo miraban, otros aparecerán para observar la nueva escena que juntos componen. Todo cambia según la perspectiva.

El casamiento engañoso es el marco o cornice de El coloquio de los perros. El alférez dice que ha oído a los perros, pero Peralta no lo cree, y el alférez no insiste demasiado. Cualquier lector lee el coloquio siempre al mismo tiempo que Peralta.

Cipión y Berganza hablan, y su discurso manifiesta el asombro que les produce el poderlo formular. Berganza cuenta la historia de la bruja Camacha, centro de su relato; si ellos fueran -como dice la bruja- hijos de la hechicera Montiela, se entendería que hablasen: es decir, sería verosímil para ellos aunque entonces sería inverosímil lo sucedido. Pero también podría ser falso el relato, y su charla quedaría sin justificación. ¿Dónde ponemos la inverosimilitud? Las palabras de Cipión son un perfecto colofón a tales reflexiones: «Todas estas cosas y las semejantes son embelecos, mentiras o apariencias del demonio; y si a nosotros nos parece ahora que tenemos algún entendimiento y razón, pues hablamos siendo verdaderamente perros, o estando en su figura, ya hemos dicho que éste es caso portentoso y jamás visto, y que, aunque le tocamos con las manos, no le habemos de dar crédito hasta tanto que el suceso dél no muestre lo que conviene que creamos» ${ }^{16}$. Y de las que, poco

15 Galatea, p. 261.

16 Novelas ejemplares, edic. cit., II, p. 321. 
después, dice Berganza, podríamos extraer una «ejemplar» lección existencial: "Y de lo que has dicho, vengo a pensar y creer que todo lo que hasta aquí hemos pasado y lo que estamos pasando es sueño, y que somos perros; pero no por esto dejemos de gozar deste bien de la habla que tenemos y de la excelencia tan grande de tener discurso humano todo el tiempo que pudiéremos» ${ }^{17}$.

Berganza cuenta la conversación de cuatro tipos o figuras que estaban «en las cuatro camas que están al cabo de la enfermería»: el arbitrista, el alquimista, el poeta, el matemático. Si ocuparon camas en la enfermería, fueron compañeros del alférez Campuzano, están en su mismo plano. Por cierto, no olvidemos que el alférez duerme mientras Peralta lee.

Berganza accede al patio de Monipodio, y la visión que nos da es distinta a la que aparece en Rinconete y Cortadillo. Ocurre cuando sirve a su amo el alguacil, que presume de valiente y en realidad sirve a Monipodio, que le protege y le permite «aparentar» su valentía: "...la noche nos halló en Triana, en una calle junto al Molino de la Pólvora. Y habiendo mi amo avizorado (como en la jácara se dice) si alguien le veía, se entró en una casa, y yo tras él y hallamos en un patio a todos los jayanes de la pendencia, sin capas ni espadas, y todos desabrochados» ${ }^{18}$. Es un elemento más del relato, relacionado con uno de los amos de Berganza. En Rinconete y Cortadillo, en cambio, la narración está centrada en ese patio y en la organización de Monipodio. Tanto es así que Rincón y Cortado forman el encuadre. Lo esencial es la figura de Monipodio y cómo rige el hampa sevillana. Pero primero accedemos también al patio, vemos los objetos, cómo se puebla de gente silenciosa; luego empezará la acción presidida por Monipodio, aunque antes habrá un descanso creado por un auténtico entremés, el de la Cariharta. (Ya Domingo Ynduráin ${ }^{19}$, y Florencio Sevilla y Antonio Rey $\operatorname{Hazas}^{20}$ han hablado de ese entremés inserto en Rinconete.)

Cervantes mezcla géneros y también registros lingüísticos. Dos de sus Novelas ejemplares son revolucionarias en ese sentido. $\mathrm{La}$ señora Cornelia se abre y se cierra con la presencia de dos personajes, los españoles don Juan y don Antonio -la acción sucede en Bolonia-, que no serán los protagonistas. Las aventuras les salen al encuentro, pero no las vivirán ellos. En realidad no hay aventuras, porque, a pesar de las apariencias, no hay dama burlada ni

17 Ibid., II, p. 323.

18 Ibid., II, p. 300.

19 "Rinconete y Cortadillo. De entremés a novela», BRAE, XLVI (1966), pp. 321-333. I, p. 46.

Introducción a la edición de Novelas ejemplares. Madrid, Espasa-Calpe, 1993, 
galán que huye. El duque de Ferrara asume en seguida su compromiso: el hermano de la dama y el galán unen sus fuerzas en el momento en que se encuentran. Si se dilata el final feliz y se suceden las peripecias es porque el ama pasa a dirigir la acción partiendo del sentido común: ¿Cómo el hermano de doña Cornelia iba a pedir ayuda a dos extranjeros? Ella lo dice con gran expresividad: « $¡ E l$ señor Lorenzo, italiano, y que se fíe de españoles y les pida favor y ayuda! Para mi ojo si tal crea -y diose ella misma una higa- ${ }^{21}$.

Se intercala además el episodio de Cornelia, la moza que se acuesta con el paje, que corresponde a un registro distinto. ¿Cómo pudo imaginar don Antonio que era Cornelia, la bellísima dama? Cuando el paje le dice: «-Señor, Santisteban, el paje del señor don Juan, desde el día que vuestras mercedes se fueron, tiene una mujer muy bonita encerrada en su aposento, y yo creo que se llama Cornelia, que así la he oído llamar» ${ }^{22} \cdot ¿$ Cómo pudo pensar en tal falta de decoro en la dama Cornelia? A pesar de ser un episodio marginal, la escena se describe con detalle. Se cuela en el mundo cortesano la vida de los criados, y el equívoco - la igualdad del nombre- crea un puente entre ellos.

No les hablo del duque como tracista (en el teatro suelen serlo los criados y las damas, casi nunca los caballeros), prolongando la acción, el relato, por el gusto de provocar reacciones y sensaciones en los otros personajes. Y no lo hago porque quiero detenerme en la sorprendente La ilustre fregona, paradójica desde su mismo título.

Los dos amigos que la protagonizan van a seguir una trayectoria común, pero desde lugares distintos. Carriazo tiene «inclinación picaresca" y a sus trece años "se desgarró" de casa de sus padres hasta licenciarse de pícaro: «Pasó por todos los grados de pícaro hasta que se graduó de maestro en las almadrabas de Zahara». Tres años llevó vida de pícaro en donde aprendió todas las artes y, al volver, "contó Carriazo a sus padres y a todos mil magníficas y luengas mentiras de cosas que le habían sucedido en los tres años de ausencia» ${ }^{23}$. Pero el veneno del gusto por tal vida perdida le lleva a la melancolía. La confesión a su amigo Avendaño conseguirá un cómplice para su nueva fuga; pero los dos amigos no llegarán a su destino. La posada del Sevillano con su hermosa fregona los detendrá. El comentario de dos mozos de mulas de Illescas sobre la belleza y la esquivez de la muchacha despertará la curiosidad de Avendaño (Carriazo está demasiado obsesionado con sus almadra-

\footnotetext{
21 Novelas ejemplares, edic. de R. Navarro, II, p. 219.

22 Ibid., II, p. 228.

23 Ibid., II, p. 73 .
} 
bas), y después, su vista lo enamorará. Como una de las figuras que pintó Georges de La Tour iluminada por una vela, así ve por primera vez a Constanza: "Y apenas hubo entrado, cuando de una sala que en el patio estaba vio salir una moza, al parecer de quince años, poco más o menos, vestida como labradora, con una vela encendida en un candelero. No puso Avendaño los ojos en el vestido y traje de la moza, sino en su rostro, que le parecía ver en él los que suelen pintar de los ángeles. Quedó suspenso y atónito de su hermosura y no acertó a preguntarle nada, tal era su suspensión y embelesamiento" ${ }^{24}$.

El amor tendrá sujeto a Avendaño y por él se disfrazará — seráde mozo de cebada. Su amigo Carriazo se queda a regañadientes, será aguador, y sus peripecias estarán acordes con su vocación. Se peleará con otro aguador, acabará en la cárcel, se jugará el asno y su cola - y lo folclórico se inserta en el relato-. La nueva identidad de los dos amigos: Tomás Pedro, mozo de mesón, y Lope Asturiano, aguador, lleva al relato al mundo de los criados. La Gallega y la Argüello pretenderán a los dos jóvenes, y ellos huyen de su asedio. El propio narrador utilizará el lenguaje de germanía: «La Argüello, que vio atraillado a su nuevo cuyo, acudió luego a la cárcel a llevarle de comer» ${ }^{25}$. Culmina ese registro en el relato con un baile a la puerta de la posada con «mulantes» y "fregatrices» bailando mientras Lope canta una chacona. Lo interrumpe un embozado con insultos: «¡Calla borracho! ¡Calla, cuero! ¡Calla, odrina, poeta de viejo, músico falso!». Pero después de recrear ese mundo de bajos fondos, el relato sigue por los cauces de la fábula compleja - según Aristóteles - y se produce la esperada anagnórisis que soluciona el amor imposible de Avendaño: Constanza será hermana de Carriazo (hija de su padre), y Cervantes aplica la obligada economía teatral a la narración. Don Diego, el padre del pícaro vocacional, confiesa la violación de la madre de Constanza. El Asturiano hará su última aparición como tal, «todos los dientes bañados en sangre» - sigue peleándose-, pero, como si de personaje de comedia se tratase, se casará con una hija del corregidor que aparece sólo para tal ocasión. Y Cervantes irá más allá: don Pedro, que pretendía a Constanza y es hijo del corregidor, que a su vez es primo de don Juan de Avendaño, se casará con una hija de éste (no mencionada antes), y se precisa además que «su padre se ofrecía a traer dispensación del parentesco». Del pasado picaresco sólo quedará el miedo de Carriazo a la pervivencia del «iDaca la cola, Asturiano!» en alguna sátira. Si la Gananciosa sabía de la eficacia de las coplas

${ }^{24}$ Ibid., II, pp. 80-81.

25 Ibid., II, p. 95 
y tranquilizaba a la Cariharta - en Rinconete y Cortadillo - con la amenaza de escribir a Repolido «un papel en coplas, que le amargue» ${ }^{26}$, Carriazo sabe que la memoria satírica, convertida en dicho popular, es larguísima.

Cervantes funde en un mismo relato el mundo de los señores y el de los criados, y lo hace con dos personajes que se mueven indistintamente en uno u otro ámbito. Y éstos quedan perfectamente perfilados. El caso amoroso se resuelve con la anagnórisis, y entonces se recupera para ese mundo cortesano a los nobles disfrazados de criados. Mientras han sido aguador y mozo de posada, los otros personajes, los episodios, a veces incluso el lenguaje, correspondían a esa esfera en la que se integraban. La maestría cervantina cambia de registro en el mismo espacio narrativo: todo depende del disfraz, del papel que se representa en el teatro del mundo, y el decoro lleva a una actuación u otra. Carriazo puede ser pícaro o noble - otra ambigüedad cervantina-, criado o señor; su ámbito de actuación varía, y la novela puede acoger a los dos en un único espacio narrativo.

Cervantes se aleja a veces de la materia narrativa aplicándole técnicas del teatro, pero otras veces se apasiona con ella y se muestra sutilmente parcial con sus personajes. No les voy a evocar el pasaje tan citado de La gitanilla -el más claro ejemplo de «irrupción subjetiva», como le llama Hatzfeld-. Les voy a recordar el doble final de El celoso extremeño : en la versión definitiva, el viejo Carrizales muere convencido del adulterio de su mujer y, por tanto, de su condición de cornudo, mientras la joven Leonora queda con su honor intacto.

El yo del narrador cerrará la novela y pondrá de manifiesto su juego de malabarista, dirá:

Sólo no sé qué fue la causa que Leonora no pudo más ahínco en desculparse y dar a entender a su celoso marido cuán limpia y sin ofensa había quedado en aquel suceso; pero la turbación le ató la lengua, y la priesa que se dio a morir su marido no dio lugar a su disculpa ${ }^{27}$.

«Sólo no sé qué fue la causa...» dice guiñando el ojo al lector, como si él realmente fuese sólo el cronista (y ha modificado el final del caso). Pero, ¿qué ha hecho en realidad?: salvar la honra de Leonora. Al viejo celoso lo ha dejado morir con el convencimiento de que era un cornudo, pero el honor de Leonora ha quedado a salvo. No se casará con Loaysa, galán holgazán y ocioso; no hay honra que reparar ni tiene porque la dama aceptar tal marido

$26 \quad$ Ibid., I, p. 252.

27 Ibid., II, p. 65. 
embustero y tramposo; el convento será un buen refugio para ella, viuda y rica. No hay mayor sutileza para apoyar a un ente de ficción.

No puede hacer lo mismo en otra de sus novelas, La fuerza de la sangre, porque la circunstancia es distinta, pero sí pone de manifiesto lo que opina de uno de sus personajes, incluso en el momento del feliz desenlace. El relato comienza intensamente, con una violación, la de Leocadia por un caballero cuyo nombre encubre el narrador y le llama Rodolfo, es rico y de ilustre sangre, pero «la inclinación torcida, la libertad demasiada y las compañías libres le hacían hacer cosas y tener atrevimientos que desdecían de su calidad y le daban renombre de atrevido» (I, pág. 366). Leocadia quedará embarazada, y su niño, Luis, tendrá siete años cuando la peripecia lleva al final feliz de la historia. Le atropella un caballo, un caballero anciano lo recoge malherido, y su madre encubierta reconocerá en la habitación en donde han atendido a su hijo, a la de su deshonra. Una vez sano su hijo, Leocadia contará su desgracia a la madre de Rodolfo, doña Estefanía. Ella, que todo lo declara a su marido, tomará las riendas de la acción - se las da Cervantes- y, como dama de comedia, urdirá una traza. Harán venir a su hijo de Nápoles diciéndole que le tienen destinada como esposa a una mujer hermosísima. Pero una vez en casa, la madre le enseñará a Rodolfo el retrato de una mujer poco agraciada. Y éste, la rechaza con un largo discurso. Expone muy claramente lo que busca en la mujer: «unos hay que buscan nobleza, otros discreción, otros dineros y otros hermosura; y yo soy destos últimos [...] La hermosura busco, la belleza quiero" (I, p. 384). La madre queda muy contenta porque ve que su traza funciona como ella espera.

Sentados a la mesa para cenar, hará entrar a Leocadia vestida de negro - no de verde como suele hacer Cervantes, porque el negro era el color adecuado a su estado-, en una especie de procesión (es una escena teatral que le gusta mucho al escritor), lleva de la mano a su hijo y va precedida de «dos doncellas alumbrándole con dos velas de cera en dos candeleros de plata» (I, p. 385). La impresión de Rodolfo es la que espera doña Estefanía; quedará prendado al instante de la belleza de Leocadia. Desmayos y lágrimas precederán al final feliz. Rodolfo querrá aún certificarse con una prueba de la identidad de Leocadia, y un crucifico que ella robó para tal fin la avala. Todo es perfecto.

Pero Cervantes nos ha ido trazando la figura de Rodolfo - cuyo nombre no cambia: no nos dice, por tanto, cuál es el «verdadero»y nunca lo ha redimido de su condición; sólo busca en la mujer la belleza; sobre su condición de "discreta» había dicho: "como una mujer no sea necia, tonta o boba, bástale que ni por aguda des- 
punte ni por boba no aproveche» (I, pág. 384). No se fía de la comprobación de sus padres y pide una prueba de la verdad de lo contado por esa dama bellísima de la que se ha enamorado. Y por si quedaba alguna duda de que Cervantes nunca se rinde ante ese joven caballero noble y rico, pero «atrevido», es la única ocasión en sus Novelas ejemplares en que añade un detalle cuando el júbilo se apodera de todos y de todo. Tras afirmar "No quedó rincón en toda la casa que no fuese visitado del júbilo, del contento y de la alegría», añade: "Y aunque la noche volaba con sus ligeras y negras alas, le parecía a Rodolfo que iba y caminaba no con alas, sino con muletas itan grande era el deseo de verse a solas con su querida esposa!» (I, pág. 389). Fernando de Herrera se enfadó mucho con Garcilaso porque en su égloga II dijo del tercer duque de Alba: «Apenas tienen fuera a don Fernando, / ardiendo y deseando estar ya echado; / al fin era dejado con su esposa» (vv. 1415-17). Rodolfo sólo era capaz del amor ferino, y Cervantes lo subraya, y con este subrayado sigue opinando sobre él. No es una joya para Leocadia, pero las circunstancias no permiten una solución mejor: es rico y noble. El modelo de la tracista doña Estefanía nos hace sospechar que Leocadia, que desde sus dieciséis años dio muestra de discreción e inteligencia, podía - una vez casada - actuar. Y vean cómo me dejo llevar por el arte cervantino y prosigo su invención sin pudor y con poca discreción.

La maestría cervantina crea esos espacios imprecisos entre lo que narra y lo que fue en ese mundo que inventa, en la forma de verlo o en la de contarlo. En su narración el lector tiene que acomodar constantemente su mirada a esos cambios de enfoques: ¿escena teatral o peripecia narrativa? ¿pícaros o señores? ¿verdad, sueño o invención? ¿buenos o malos? La ambigüedad cervantina, muestra de su inmensa sabiduría narrativa, tiene muchas más formas. El lector siempre encuentra en sus obras ese espacio indefinido para la reflexión. Como dice Francisco Ayala, tan cervantino él mismo: «A Cervantes la realidad del mundo moral se le aparece como problemática, y por eso lo que él nos propone no es una solución, sino el problema mismo, para que, debatiéndolo entre sus términos, tratemos de hallarla con nuestros recursos personales en el foro de nuestra libre intimidad ${ }^{28}$.

ROSA NAVARRO DURÁN Universidad de Barcelona

28 FRANCISCO AYALA, "La técnica de composición en Cervantes», en Cervantes y Quevedo. Barcelona, Ariel, 1984, p. 78. 